\title{
RELATÓ RIO
}

\section{EGRÉGIA CONGREGAÇÃO}

Cumprindo preceito regimental, tenho a honra de apresentar a essa doutíssima Congregação o relatório das atividades didáticas e administrativas verificadas no ano letivo de mil novecentos e sessenta e sete.

\section{CORPO DOCENTE}

A Faculdade de Direito, no ano letivo de 1967, dispõe, para os vinte e três cargos de professôres catedráticos, que integram o seu quadro, de quinze titulares.

As Cadeiras vagas estão sendo ocupadas: por: um Professor Auxiliar de Ensino, Ernani Almeida de Abreu, de Direito Comercial, do $4 .^{\circ}$ ano; um Professor Catedrático, Rubens Requião, 3. ano; um Catedrático interino, Professor José Munhoz de Mello, Direito Constitucional, 2. ${ }^{\circ}$ ano; dois Professôres de Ensino Superior, Alcides Munhoz Neto, Direito Penal, do $2 .^{\circ}$ ano, e José Petrelli Gastaldi, Economia Política, do $1 .^{\circ}$ ano; três Professôres Contratados, DocentesLivres, Euclides de Mesquita (que se encontra afastado), Gaspar Luiz Lacerda Pinto, do $4 .^{\circ}$ ano, e José Lamartine Corrêa de Oliveira, do 5. ano, regendo as Cadeiras de Direito Civil; um Instrutor de Ensino Superior designado pelo Conselho Técnico-Administrativo, para a Cadeira de Direito Internacional Privado, 5.0 ano, Henrique Chesneau Lenz Cesar.

\section{PROFESSÔRES AUSENTES}

Permaneceram durante o corrente ano à disposição: do Ministério da Educação e Cultura o Professor Humberto Grande; da Escola Superior de Guerra, o Professor Omar Gonçalves da Motta, da Cadeira de Direito do Trabalho; da Faculdade Nacional de Direito da Universidade Federal do Brasil, o Instrutor Milton Tesserolli, da Cadeira de Direito Romano; do Ministério da Agricultura, o Instrutor Ruy Corrêa Lopes, da Cadeira de Introdução à Ciência do Direito.

\section{CONTRATAÇÃO DE INSTRUTORES}

Foram renovados, no presente ano, os contratos dos Instrutores René Ariel Dotti, para a Cadeira de Direito Penal; Manoel Eugênio Marques Munhoz, para a Cadeira de Direito Administrativo, João 
Régis Fassbender Teixeira, Docente-Livre, para a Cadeira de Direito do Trabalho; José Ribamar Gaspar Ferreira, para a Cadeira de Ciência das Finanças; Álvaro Floriano Paczkoski, para a Cadeira de Teoria Geral do Estado; Fernando Andrade de Oliveira, para a Cadeira de Direito do Trabalho; Rogério Fagundes, para o Escritório de Assistência Judiciária da Faculdade.

Foram contratados, no corrente ano, como Auxiliares de Ensino os Bacharéis: José Eduardo Soares de Camargo, para a Cadeira de Direito Romano, Juarez Estevam Xavier Tavares, para a Cadeira de Direito Penal, Hilton Ritzmann, para a Cadeira de Direito Comercial, Joaquim Roberto Munhoz de Mello, para a Cadeira de Direito Judiciário Civil, e Rogério Fagundes, para a Cadeira de Direito Judiciário Penal.

\section{APOSENTADORIA COMPULSÓRIA}

Foram aposentados os Professôres Catedráticos: Carlos de Britto Pereira, da Cadeira de Direito Comercial e João Alves da Rocha Loures, da Cadeira de Ciência das Finanças.

\section{EXAMES DE SUFICIÊNCIA}

Prestaram Exames de Suficiência os seguintes Bacharéis: Juarez Estevam Xavier Tavares, para a Cadeira de Direito Penal, 3.0 ano, José Eduardo Soares de Camargo, para a Cadeira de Direito Romano, $1 .^{\circ}$ ano; Hilton Ritzmann, para a Cadeira de Direito Comercial, 3. ano, Joaquim Roberto Munhoz de Mello, para a Cadeira de Direito Judiciário Civil, $4 .^{\circ}$ ano, e Rogério Fagundes, para a Cadeira de Direito Judiciário Penal, $5 .^{\circ}$ ano.

\section{REGULAMENTO INTERNO}

Acha-se no Conselho Federal de Educação, para a sua aprovação final, o anteprojeto do Novo Regimento Interno da Faculdade de Direito.

\section{SERVIÇO DE ASSISTÊNCIA JUDICIÁRIA}

Orientado pelo advogado Rogério Fagundes, contratado pela Reitoria da Universidade, funcionou regularmente o Escritório de Assistencia Judiciária desta Faculdade, com apreciável rendimento.

\section{ESCOLA téCNICA de COMÉrCio}

Com 547 alunos matriculados, entre os quais, 169 pertencem à última série, e encerrando o movimento financeiro com superavit, a Escola Técnica de Comércio, anexa a esta Faculdade, cumpriu 
nova etapa de suas fecundas realizações, decorrentes da dedicação e esfôrços dos seus ilustres professôres e pessoal Administrativo.

\section{CONGREGAÇÃO}

Durante o ano letivo de 1967 a Congregação da Faculdade realizou 7 sessões.

\section{CONSELHO TÉCNICO-ADMINISTRATIVO}

Foram realizadas 22 sessões do Conselho Técnico-Administrativo, atualmente composto dos Professôres Ildefonso Marques, Presidente, Ary Florencio Guimarães, Secretário, Altino Portugal Soares Pereira, José Nicolau dos Santos, Rubens Requião e Gaspar Luiz Lacerda Pinto, e o acadêmico Rubens Corrêa, representante do corpo discente.

\section{FALECIMENTO}

Tivemos a lamentar os falecimentos dos Professôres Ernani Guarita Cartaxo e Laertes de Macedo Munhoz, homenageados pòstumamente pelo egrégio Conselho Técnico-Administrativo e pela colenda Congregação, em sessões de 23 de novembro e 28 de dezembro, do corrente ano, respectivamente.

\section{ATIVIDADES DIDÁTICAS}

\section{AULA INAUGURAL}

No dia $1 .^{\circ}$ de março do corrente ano, no Salão Nobre, realizouse a aula inaugural do curso de bacharelado desta Faculdade, proferida pelo Professor Carlos Araújo de Britto Pereira, Catedrático de Direito Comercial.

\section{CONCURSO DE HABILITAÇÃO}

Realizaram-se, na segunda quinzena de fevereiro, os exames de concurso de habilitação à matrícula na primeira série do Curso de bacharelado.

Inscreveram-se 379 candidatos. Dêsses, foram aprovados e classificados 100 e aprovados e não classificados 6 .

\section{MATRÍCULA}

De 16 a 28 de fevereiro, época regulamentar, matricularam-se no curso de bacharelado desta Faculdade:

No $1 .^{\circ}$ ano - 110 alunos; 


$$
\begin{aligned}
& \text { No } 2 .^{\circ} \text { ano }-135 \text { alunos; } \\
& \text { No } 3 .^{\circ} \text { ano }-134 \text { alunos; } \\
& \text { No } 4 .^{\circ} \text { ano }-139 \text { alunos; } \\
& \text { No } 5 .^{\circ} \text { ano }-113 \text { alunos. } \\
& \text { TOTAL ................ } 631 \text { alunos. }
\end{aligned}
$$

\section{FREQUENCIA}

Durante o correntre ano, constatou-se que não conseguiram os $75 \%$ da freqüência exigida por lei, em uma ou mais cadeiras das respectivas séries: no $1 .^{\circ}$ ano -20 alunos no $2 .^{\circ}$ ano -31 alunos; no $3 .^{\circ}$ ano -53 alunos; no $4 .^{\circ}$ ano -36 alunos; no $5 .^{\circ}$ ano -22 alunos; conforme a seguinte especificação por disciplina:

1. ano - Economia Política: 8 alunos. Direito Romano: 13 alunos.

Teoria Geral do Estado: 11 alunos. Introdução à Ciência do Direito: 11 alunos.

2. ano - Direito Civil: 18 alunos. Direito Penal: 24 alunos.

Direito Constitucional: 24 alunos.

Ciência das Finanças: 23 alunos.

3. ano - Direito Civil: 30 alunos. Direito Penal: 27 alunos. Direito Comercial: 39 alunos.

Direito Internacional Público: 23 alunos.

Direito do Trabalho: 28 alunos.

4. ano - Direito Civil: 27 alunos.

Direito Judiciário Civil: 28 alunos.

Direito Penal: 30 alunos.

Direito Comercial: 30 alunos.

Medicina Legal: 27 alunos.

1. ano - Direito Civil: 14 alunos.

Direito Judiciário Civil: 14 alunos.

Direito Judiciário Penal: 10 alunos.

Direito Administrativo: 14 alunos.

Direito Internacional Privado: 9 alunos.

Não alcançaram 25\% de freqüência, em uma ou mais Cadeiras das respectivas séries e de conseqüência não prestarão exames em segunda época (art. 166, C, do Regimento Interno):

$$
\begin{aligned}
& 10^{\circ} \text { ano - } 5 \text { alunos. } \\
& 2 .^{\circ} \text { ano - } 13 \text { alunos. }
\end{aligned}
$$




$$
\begin{aligned}
& 3 .^{\circ} \text { ano - } 14 \text { alunos. } \\
& 4 .^{\circ} \text { ano - } 3 \text { alunos. }
\end{aligned}
$$

\section{AULAS DADAS}

$E^{\prime}$ o seguinte o quadro das aulas dadas pelos senhores professôres, durante o ano letivo de 1967:

1. ano - Introdução à Ciência do Direito: 62 aulas. Economia Política: 90 aulas.

Direito Romano: 80 aulas.

Teoria Geral do Estado: 74 aulas.

2. ${ }^{\circ}$ ano - Direito Civil: 81 aulas.

Direito Penal: 84 aulas.

Direito Constitucional: 75 aulas.

Ciências das Finanças: 82 aulas.

3. ano - Direito Civil: 85 aulas.

Direito Penal: 88 aulas.

Direito do Trabalho: 81 aulas.

Direito Comercial: 66 aulas.

Direito Internacional Público: 71 aulas.

4. ano - Direito Comercial: 80 aulas.

Direito Penal: 64 aulas.

Direito Judiciário Civil: 77 aulas.

Direito Civil: 53 aulas.

Medicina Legal: 89 aulas.

5. ano - Direito Judiciário Penal: 84 aulas.

Direito Judiciário Civil: 79 aulas.

Direito Administrativo: 68 aulas.

Direito Civil: 86 aulas.

Direito Internacional Privado: 88 aulas.

\section{GUIAS DE TRANSFERENCIA}

Foram recebidas, durante o ano, 3 guias de transferência sendo uma para $\circ 2 .^{\circ}$ ano, duas para $\circ 4 .^{\circ}$ ano.

Foram expedidas, 16 guias de transferência, sendo cinco do $1 .^{\circ}$ ano, quatro do $2 .^{\circ}$ ano, quatro do $3 .^{\circ}$ ano e três do $4 .^{\circ}$ ano.

\section{COLAÇÃO DE GRAU}

A colação de grau realizar-se-á em março de 1968. 


\section{BIBLIOTECA}

A Biblioteca da Faculdade de Direito da Universidade Federal do Paraná foi inaugurada em 22 de setembro de 1955.

Durante o corrente ano, o movimento de aquisições, inclusive periódicos e doações, totalizou 630 volumes, no total de NCR\$ .... $8.000,00$.

No ano de 1966, o acêrvo da Biblioteca se compunha de 33.500 volumes, inclusive doações, alcançando no ano de 1967 a casa dos 34. 130. guinte:

A resenhá das aquisições feitas nos dois últimos anos, é a se-

ANO

1966

1967
VOLUMES

620

630
PRÊÇO

NCR\$ $8.000,00$

NCR\$ $8.000,00$

$\mathrm{Na}$ Biblioteca Fixa foi o seguinte o movimento de obras consultadas:

Em 1966: 1727

Em 1967: 1678

Foram retirados, para consulta, pelos Senhores Professôres:

Em 1966: 331

Em 1967: 304

Estatística das obras consultadas, no ano de 1967:

\section{ASSUNTO}

000 - Obras gerais

100 - Filosofia

200 - Religião

300 - Ciências Sociais

400 - Filologia

500 - Ciências puras

600 - Ciências aplicadas

700 - Belas artes

800 - Literatura

900 - História, geogr., biogr.

REVISTAS
NÚMERO DE CONSULTAS

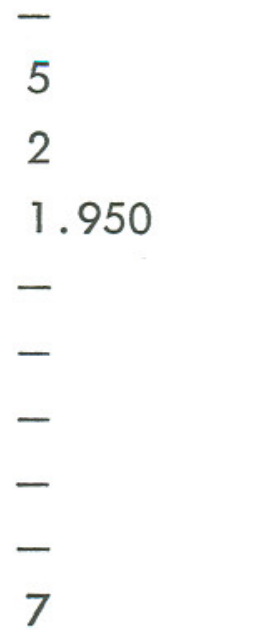


Estatística por idioma:

IDIOMA

PORTUGUÊS

ESPANHOL

ITALIANO

FRANCÊS

INGLÊS
NÚMERO DE CONSULTAS

1.830

45

40

50

8

TOTAL: 1982

Estatística mensal:

\section{MEESES}

Janeiro

Fevereiro

Março

Abril

Maio

Junho

Julho

Agôsto

Setembro

Outubro

Novembro

Dezembro

\section{NÚMERO DE CONSULTAS}

35

19

68

487

259

278

85

170

207

188

186

TOTAL: 1982

Assim, o movimento de consultas da Biblioteca Fixa, incluindo os Senhores Professôres, foi de 1982 volumes.

\section{BIBLIOTECA CIRCULANTE}

A Biblioteca Circulante, inaugurada em 21 de maio de 1962, teve seu Regulamento Interno aprovado em sessão do Conselho Técnico Administrativo de 5 de outubro de 1962.

$\mathrm{Na}$ referida Biblioteca os alunos podem retirar livros para consulta domiciliar.

seguinte: 95.

O número de inscrições de alunos, no corrente ano, foi o

\section{Estatística por assunto}

Obras gerais

Filosofia

Religião

Ciências sociais 


\begin{tabular}{lr} 
Direito: geral & 4 \\
Teoria & 49 \\
Filosofia do Direito & 21 \\
Medicina legal & 114 \\
Direito intern. público & 136 \\
Direito intern. privado & 133 \\
Direito constitucional & 162 \\
Processo penal & 227 \\
Direito Penal & 593 \\
Direito civil & 695 \\
Direito comercial & 303 \\
Processo civil & 394 \\
Direito romano & 51 \\
Direito social & 114 \\
Direito administrativo & 92 \\
Filosofia & - \\
Ciências puras & 1 \\
Ciências aplicadas & 1 \\
Belas artes & 1 \\
Literatura & 59 \\
Hist. Geografia & 13 \\
& \multicolumn{1}{c}{ TOTAL }
\end{tabular}

\section{Estatística mensal:}

\begin{tabular}{lr} 
Janeiro & 49 \\
Fevereiro & 80 \\
Março & 281 \\
Abril & 566 \\
Maio & 262 \\
Junho & 495 \\
Julho & 47 \\
Setembro & 452 \\
Outubro & 356 \\
Novembro & 555 \\
Dezembro & 30 \\
\multicolumn{1}{c}{ TOTAL } & 3.495
\end{tabular}

\section{Estatística por idioma}

Português:

3.465

Espanhol:

Francês:

Italiano:

Latim:

\section{TOTAL}

